\title{
At Least Three Transporters Likely Mediate Threonine Uptake Needed for Mouse Embryonic Stem Cell Proliferation
}

\author{
Tara M. Formisano * and Lon J. Van Winkle \\ Department of Biochemistry, Midwestern University College of Health Science, Downers Grove, IL, USA
}

\section{OPEN ACCESS}

Edited by:

Karthikeyan Narayanan, Institute of Bioengineering and

Nanotechnology, Singapore

Reviewed by:

Yuhua Sun

Chinese Academy of Science, China

Raman Chandrasekar,

Kansas State University, USA

*Correspondence:

Tara M. Formisano

tformisano59@midwestern.edu

Specialty section:

This article was submitted to

Stem Cell Treatments,

a section of the journal

Frontiers in Cell and Developmental

Biology

Received: 27 January 2016 Accepted: 29 February 2016

Published: 15 March 2016

Citation:

Formisano TM and Van Winkle LJ (2016) At Least Three Transporters

Likely Mediate Threonine Uptake Needed for Mouse Embryonic Stem Cell Proliferation.

Front. Cell Dev. Biol. 4:17. doi: 10.3389/fcell.2016.00017
Stem cells are at the forefront of current regenerative and biomedical research. Thus, there exists an imperative and urgent need to understand the mechanisms that drive stem cell function in order to exploit their use as a therapeutic tool. Amino acids are potent inducers of signaling cascades that drive stem cell proliferation and differentiation. With a focus on mouse embryonic stem (mES) cells, Threonine (Thr) is the only amino acid required in culture media for $\mathrm{mES}$ cell proliferation. Current research associates this need for Thr with threonine dehydrogenase (TDH), which catabolizes Thr to glycine and acetyl-CoA in mES cells. This theory depends, in part, on the ability of 3- hydroxynorvaline (3-HNV) to inhibit both TDH and mES cell proliferation. However, the concentration of 3-HNV needed to inhibit mES cell proliferation is more than an order of magnitude less than its apparent $\mathrm{K}_{i}$ for TDH inhibition. Additionally, 3-HNV inhibits human embryonic stem (hES) cell proliferation, but hES cells do not express a functional tdh gene. Such findings indicate another mechanism for Thr stimulated mES and hES cell proliferation. Since amino acid transporters may be inducers of signaling cascades, we characterized the Thr transport systems in mES cells. We found that there is a $\mathrm{Na}^{+}$-dependent and a $\mathrm{Na}^{+}$-independent component of substrate-saturable transport, with the $\mathrm{Na}^{+}$-dependent component predominating. We also found that of 20 amino acids tested, the amino acids that were the strongest inhibitors of the $\mathrm{Na}^{+}$-dependent component of radiolabeled Thr transport were Ser, Cys, 4-OH-Pro, Asn, Met, and non-radiolabeled Thr itself. Such findings are consistent with characteristics of the ASC transport system, suggesting that this ASC system is responsible for the majority of Thr transport in mES cells. We confirmed expression of mRNA encoding the ASC system transporters, ASCT1 and ASCT2, in mES cells using RT-PCR. In conclusion, mES cells likely express at least three transporters of Thr; at least two $\mathrm{Na}^{+}$-dependent transporters and one $\mathrm{Na}^{+}$-independent one.

Keywords: mES cells, cell proliferation, threonine, amino acid transport system ASC, amino acid transport system $\mathbf{L}$ 


\section{INTRODUCTION}

Stem cells are one of the primary focuses in current regenerative medicine and biomedical research. With their vast developmental potential, proliferative competence, and genetic stability, stem cells have noteworthy therapeutic potential. In fact, stem cells have the potential to treat a wide variety of diseases and injuries including neurological disease, blindness, Type I Diabetes Mellitus, Parkinson's disease, Leukemia, and spinal cord injuries (Amit et al., 2000; Puri and Nagy, 2012). Thus, there is a race to understand stem cell biology in order to exploit their potential uses.

In an effort to understand stem cell function, some research has focused on the role of amino acids in stem cell proliferation and differentiation (Van Winkle, 2013). mES cell proliferation and maintenance of the undifferentiated state depends exclusively on the presence of $\mathrm{Thr}$ in the culture medium (Alexander et al., 2011). These authors proposed a need for Thr owing to its rapid catabolism via threonine dehydrogenase (TDH), an enzyme abundant in mES cells. The selective TDH inhibitor, 3-HNV, inhibits mES cell proliferation, and Thr rescues the cells from this inhibition (Wang et al., 2009). A sharp contradiction, however, can be seen when comparing mES cells and hES cells. hES cells seem to rely in a similar way on Thr for proliferation, but hES cells produce inactive TDH (Darling et al., 2000; Edgar, 2002; Van Winkle et al., 2014). In addition, the Thr and 3-HNV concentrations needed for mES cell proliferation or inhibition of proliferation, respectively, are more than an order of magnitude less than the apparent $\mathrm{K}_{\mathrm{m}}$ and $\mathrm{K}_{\mathrm{i}}$ values for the interaction of Thr or 3-HNV with TDH (Van Winkle et al., 2014). These results support the conclusion that TDH is not the site of 3-HNV and Thr action in hES cells, and it may not be the only site of their action in mES cells.

Previous studies attribute the need for Thr by mES cells to its rapid catabolism via TDH. These studies found that the mRNA levels of TDH were 1000 times higher in mES cells compared to differentiated cells (Ochocki and Simon, 2013). Much research is consistent with the conclusion that TDH catabolism of Thr is responsible for the unique one carbon metabolic state of mES cells (Han et al., 2013). Specifically, $\mathrm{TDH}$ is a mitochondrial enzyme that hydrolyzes Thr into glycine and acetyl-coA (Han et al., 2013). Glycine is used to promote $\mathrm{mES}$ cell one carbon metabolism while acetyl-coA is oxidized in the TCA cycle (Han et al., 2013). This one carbon metabolism supports the purine and the pyrimidine (thymidine) biosynthesis needed for mES cell proliferation (Ochocki and Simon, 2013). Furthermore, inhibition of TDH eventually causes mES cell death (Han et al., 2013). Thus, Thr breakdown products supply metabolic pathways with substrates needed for rapid mES cell proliferation.

Threonine's role in mES cell proliferation is likely more complex, however. Studies indicate that Thr is a very potent activator of several critical signaling pathways. One such study explored Thr's role in regulating embryonic stem (ES) cell transition through the G1/S phase of the cell cycle (Ryu and Han, 2011). Specifically, this study found that Thr stimulates ES cell transition through the G1/S phase by activating lipid raft/caveolae-dependent signaling pathways, including PI3K/Akt, MAPKs, mTOR, p7056k, and 4E-BP1 (Ryu and Han, 2011). The induction of these signaling pathways leads to the transcription of c-Myc, which is a potent regulator of cell proliferation (Ryu and Han, 2011). Moreover, this study also found that Thr will restore and increase cyclin D1 and cyclin E, both of which are the rate limiting activators on the G1 to S phase transition in the cell cycle required for proliferation (Ryu and Han, 2011). The lipid raft dependent signaling could be through a direct association of Thr and its transporter with the raft (Ryu and Han, 2011). Thr also may be needed intracellularly for signaling, which would depend on uptake of Thr by the cells (Ryu and Han, 2011). All of these studies support the need to characterize Thr transport in ES cells.

Amino transport systems were originally categorized according to their substrate selectivity (cationic, anionic, or zwitterionic amino acids) and $\mathrm{Na}^{+}$dependence (Van Winkle, 2013). Numerous amino acid transport systems have been characterized and the transporter proteins comprising the systems identified (Placín et al., 1998; Van Winkle, 2013). Systems that could transport $\mathrm{Thr}$ well include the $\mathrm{Na}^{+}$-independent systems, L (named for Leu) and $\mathrm{b}^{0,+}$ (selective for Arg), and the $\mathrm{Na}^{+}$-dependent systems, $\mathrm{B}^{0,+}$ (selective for Leu, Ile, and Trp), A (named for Ala) and ASC (named for Ala, Ser, and Cys; Van Winkle, 2013). Of these, system ASC is particularly attractive as a possible Thr transporter in $\mathrm{mES}$ cells because this system tolerates hydroxyl and sulfahydryl groups at C3 or C4 very well (Utsunomiya-Tate et al., 1996; Pinilla-Tenas et al., 2003). Thr has such a hydroxyl group rendering if a good substrate for this system. Nevertheless, when amino acid transport has not been studied in a particular cell type, it should be characterized first, rather than assuming that certain amino acid transporters are present in those cells (Van Winkle, 2013). Since Thr transport has not been characterized previously in mES cells, we began to characterize it as described in these studies.

\section{METHODS mES Cell Culture}

ATCC American Tissue Type Culture Collection CE1 Mouse Embryonic Stem Cells were placed in T75 Tissue Culture Flasks with $\mathrm{mES}$ cell media for 2 days. Media included DMEM F12 (Gibco), Leukemia Inhibiting Factor (Gibco), Fetal Bovine Serum (Bio west), non-essential amino acid (Gibco), Penicillinstreptomycin (Hydroclone) and glutamine solution containing DMEM F12 (Gibco), glutamine (Sigma), and 2-mercaptoethanol (Bio Rad). After 2 days of growth, the cells were trypsinized with Tryspin-EDTA (Gibco) for $5 \mathrm{~min}$ and then collected in a $15 \mathrm{ml}$ conical centrifuge tube. The cells were spun down at $3400 \mathrm{rpm}$ for $1 \mathrm{~min}$ and then re-suspended in $5 \mathrm{ml}$ of $\mathrm{mES}$ cell media by trituration. Cells were then placed in approximately $20 \mathrm{ml}$ of mES cell media in a $50 \mathrm{ml}$ conical tube and counted using a TC20 Automated Cell Counter (Bio Rad). They were then brought to a concentration of $2 \times 10^{5}$ cells $/ \mathrm{ml} \mathrm{mES} \mathrm{cell} \mathrm{media.} 1 \mathrm{ml}$ of $\mathrm{mES}$ cell suspension was plated into each well in a 6 well tissue culture treated plate and then placed in $5 \% \mathrm{CO}_{2}, 37^{\circ} \mathrm{C}, 100 \%$ humidity incubator (Binder) for 1 day. On day 2, media was replaced 
with fresh mES cell media. The cells were placed back into the incubator. On day 3 , experimental procedures were performed.

\section{Time Course}

mES cell media was aspirated off of the 6 well plates containing $\mathrm{mES}$ cells using an in house vacuum system. $1 \mathrm{ml}$ of the different uptake buffers (with $\mathrm{Na}^{+}$and without $\mathrm{Na}^{+}$) containing $50 \mathrm{uM}$ radioactive labeled Thr was added to their respective wells. The uptake buffers tested include those containing $140 \mathrm{mM} \mathrm{NaCl}$, $\mathrm{LiCl}$, Choline $\mathrm{Cl}$, and $\mathrm{KCl}$, and $280 \mathrm{mM}$ Mannitol. The uptake buffer stock solution also contained $25 \mathrm{mM}$ HEPES+ Tris $(\mathrm{pH}=$

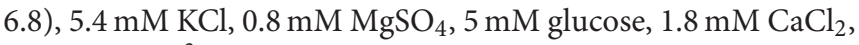
and $50 \mathrm{uM}\left[{ }^{3} \mathrm{H}\right]-\mathrm{Thr}(20 \mathrm{Ci} / \mathrm{mmol}$ in stock solution supplied by American Radiolabeled Chemicals, Saint Louis, MO). The cells were incubated up to $10 \mathrm{~min}$ at $37^{\circ} \mathrm{C}, 100 \%$ Humidity (Napco). After each incubation period, $20 \mathrm{uL}$ of the sample was taken from each well and placed into scintillation vials. The remaining radioactive treatment was aspirated off. Cells were then washed 6 times with the appropriate with $\mathrm{Na}^{+}$or without $\mathrm{Na}^{+}$uptake buffer (NOTE: This buffer did not contain any radiolabeled Thr). The 6th wash was collected and placed in a second set of scintillation vials to check for thoroughness of washing. The cells were then treated with $1 \mathrm{ml} 4 \%$ SDS detergent for $2 \mathrm{~min}$. The sample was collected into a 3 rd set of scintillation vials. $5 \mathrm{ml}$ of Scintillation cocktail Econ2 (Fischer Scientific) was added to all scintillation vials. All vials were placed in a Beckmann LS6500 Beta liquid scintillation counter and counted for $10 \mathrm{~min}$. Experiments were performed 1-3 times with 1-3 replicate determinations as indicated in Figure legends.

\section{Radiolabeling Amino Acid Inhibitor Experiment}

mES cell media was aspirated off of the 6 well plates containing $\mathrm{mES}$ cells using an in house vacuum system. A radioactive solution containing uptake buffer, $50 \mathrm{uM}$ radiolabeled $\mathrm{Thr}$, and $10 \mathrm{mM}$ of various potential amino acid inhibitors (Glu, Ser, Lys, Gly, Leu, MeAIB, Pro, Asp, Thr, Sar, Cys, Asn, Ala, Met, His, Gln, Arg, Tyr, BCH at 5mM, 4-OH-Pro) was prepared. Each study was repeated using the $\mathrm{Na}^{+}$containing uptake buffer and with the no- $\mathrm{Na}^{+}$containing uptake buffer, Mannitol. The stock uptake buffer solution contained $25 \mathrm{mM}$ HEPES + Tris $(\mathrm{pH}=$

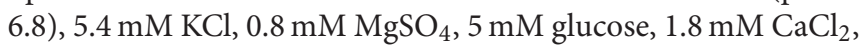
and $50 \mathrm{uM}\left[{ }^{3} \mathrm{H}\right]-\mathrm{Thr}$. The $\mathrm{Na}^{+}$containing buffer also contained $140 \mathrm{mM} \mathrm{NaCl}$ and the no- $\mathrm{Na}^{+}$containing uptake buffer also contained $280 \mathrm{mM}$ Mannitol. $1 \mathrm{ml}$ of the radiolabeled Thr uptake solution was added to the appropriate well in the 6 well plates and then incubated for $10 \mathrm{~min}$ at $37^{\circ} \mathrm{C}, 100 \%$ humidity. After $10 \mathrm{~min}, 20 \mathrm{uL}$ of the sample was taken from each well and placed into scintillation vials. The remaining radioactive treatment was aspirated off. The cells were washed 6 times with the appropriate $\mathrm{NaCl}$ or Mannitol uptake buffer. The 6th wash was collected and placed in a second set of scintillation vials to check for thoroughness of washing. The cells were then treated with $1 \mathrm{ml}$ $4 \%$ SDS detergent for $1 \mathrm{~min}$. The sample was collected into the scintillation vials. $5 \mathrm{ml}$ of Scintillation cocktail Econ2 (Fischer Scientific) was added to all scintillation vials. All vials were placed in a Beckmann LS6500 Beta liquid scintillation counter and counted for $10 \mathrm{~min}$. Experiments were performed 1-3 times with 1-3 replicate determinations as indicated in Figure legends.

Once the less complete inhibitors of Thr uptake were identified from the more complete inhibitor series above, Leu and Pro, were used in the same experimental procedure using $0.5,1.0$, 5.0, 10.0, $20.0 \mathrm{mM}$ of Leu and Pro, respectively, and $20 \mathrm{mM}$ nonradioactive Thr in the $\mathrm{NaCl}$ uptake buffer. Our control was $50 \mathrm{uM}$ ${ }^{3} \mathrm{H}$ Thr uptake solution with no amino acid inhibitor.

Once the complete inhibitors of Thr uptake were identified from the complete inhibitor series, we conducted the same experimental procedure using $500 \mathrm{uM}$ of only those complete inhibitors (Ser, Ala, Thr, Cys, Asn, 3-HNV, Met, 4-OH-Pro) in both the $\mathrm{NaCl}$ uptake buffer and no- $\mathrm{Na}^{+}$uptake buffer, Choline Chloride. Our control was $50 \mathrm{uM}^{3} \mathrm{H}$ Thr uptake solution with no amino acid inhibitor.

\section{RT-PCR}

For RNA isolation, approximately $5 \times 10^{6}$ cells were spun down to a pellet at $300 \times \mathrm{g}$ for $5 \mathrm{~min}$. $350 \mathrm{uL}$ of Buffer RLT was added to lyse the pelleted cells. Total RNA was then isolated from the cells using the RNeasy Mini RNA Isolation Kit using the manufacturer protocol (Qiagen) (NOTE: The QIAshredder spin column protocol option was used). The RNA was quantified by measuring the absorbance at $260 \mathrm{~nm}$. Typical total RNA yield was $\sim 2300 \mathrm{ng} / \mathrm{ul}$. The technique for RT-PCR was performed using 2 ug total RNA from the mES cells and the QIAGEN OneStep RT-PCR kit protocol that was recommended by the manufacturer. 0.6 uM PrimeTime qPCR Primers were used (Integrated DNA Technologies). The Slcla4 and Slcla5 qPCR primers amplify a $\sim 150$ bp PCR product. The sequence of the primers for Slc1a4 (ASCT1; Marin et al., 2000) are as follows: forward primer:

5'-TCATCCCTTCCACATCTGTTAC-3'; reverse primer:

$5^{\prime}$ - CCTGTTCCCTTCCAATCTTGT-3'. The sequence of the primers for Slc1a5 (ASCT2; Marin et al., 2000) are as follows: forward primer:

5' - CCATTCTTCTCCTCTACACACTTC-3'; reverse primer:

$5^{\prime}$ - CСТCTCATCTACTTCCTCTTCAC-3'. The no-template sample consisted of molecular biology grade water instead of RNA. The PrimeTime qPCR Primer stock solution was made to a concentration of $10 \times$ according to the manufacturer's protocol (Integrated DNA Technologies). The RT-PCR conditions used were $30 \mathrm{~min}$ at $50^{\circ} \mathrm{C}, 15 \mathrm{~min}$ at $95^{\circ} \mathrm{C}, 1 \mathrm{~min}$ at $94^{\circ} \mathrm{C}, 1 \mathrm{~min}$ at $58^{\circ} \mathrm{C}, 1 \mathrm{~min}$ at $72^{\circ} \mathrm{C}$, followed by 40 cycles of $1 \mathrm{~min}$ at $94^{\circ} \mathrm{C}$, and then $10 \mathrm{~min}$ at $72^{\circ} \mathrm{C}$.

\section{Gel Electrophoresis}

The gel was loaded and samples were electrophoresed at $100 \mathrm{~V}$ for $45 \mathrm{~min}$ in $1 \times$ TAE buffer with ethidium bromide $(0.5 \mathrm{ug} / \mathrm{ml})$. The DNA was visualized using a UV transilluminator. Samples of cDNA were sent to Molecular Cloning Laboratories (San Francisco, CA) for sequencing. The sequences of the cDNAs corresponded to the sequences anticipated for those segments of ASCT1 and ASCT2 mRNA. The Slcla4 forward and reverse primers (ASCT1) had a $98 \%$ match. The Slcla5 forward and reverse primers (ASCT2) had a 99\% match (Molecular Cloning Laboratories). 


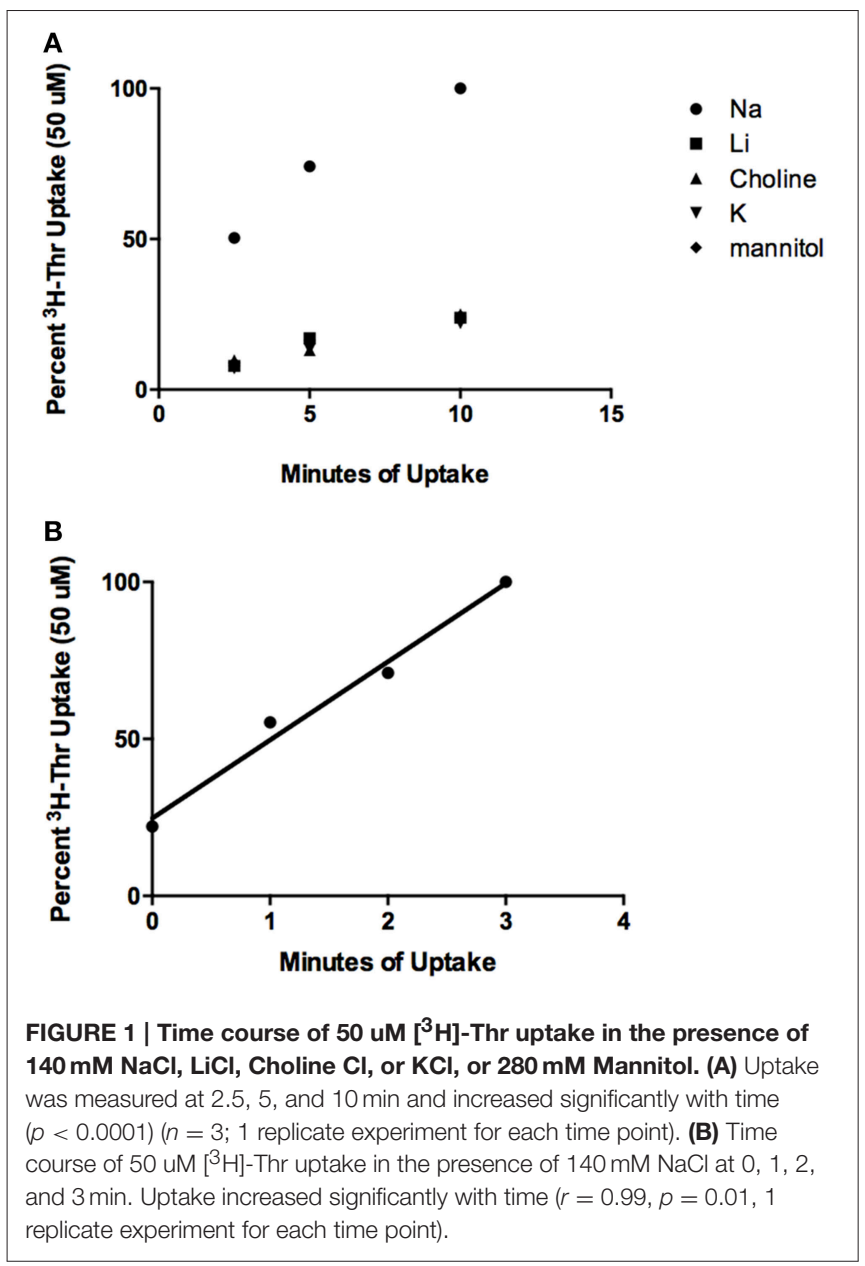

\section{RESULTS}

\section{Threonine has a $\mathrm{Na}^{+}$-Dependent and $\mathrm{Na}^{+}$-Independent Component of Transport}

From the time course studies, Thr uptake was much more rapid in the presence of $\mathrm{Na}^{+}$than in its absence (Figure 1A, $p<0.003$, Effect Size $=0.96)$. In both instances, Thr uptake increased nearly linearly with time for at least $10 \mathrm{~min}(p<0.0001$ for uptake in the absence of $\mathrm{Na}^{+}$shown in the figure and in the presence of $\mathrm{Na}^{+}$ in a separate series of experiments with three determinations at each time point). The correlation coefficients for the increases of Thr uptake with time were: $r_{\mathrm{Na}+}=0.97, r_{\mathrm{no} \mathrm{Na}+}=0.96$. The correlation coefficient for the increase in Thr uptake over 3 min was $r=0.99$ (Figure 1B). Some binding of Thr to the cells also likely occurred since $\left[{ }^{3} \mathrm{H}\right]$-Thr was associated with mES cells even after their exposure to $\left[{ }^{3} \mathrm{H}\right]$-Thr for only a few seconds, as indicated at the 0 time point in Figure 1B.

\section{Threonine Transport Is Inhibited to Varying Degrees by Different Amino Acids in the Presence or Absence of $\mathrm{Na}^{+}$}

In the presence of $\mathrm{Na}^{+},\left[{ }^{3} \mathrm{H}\right]-\mathrm{Thr}$ transport was significantly inhibited $(p<0.05)$ by Ser, Gly, Leu, Pro, Sar, Cys Asn, Ala,

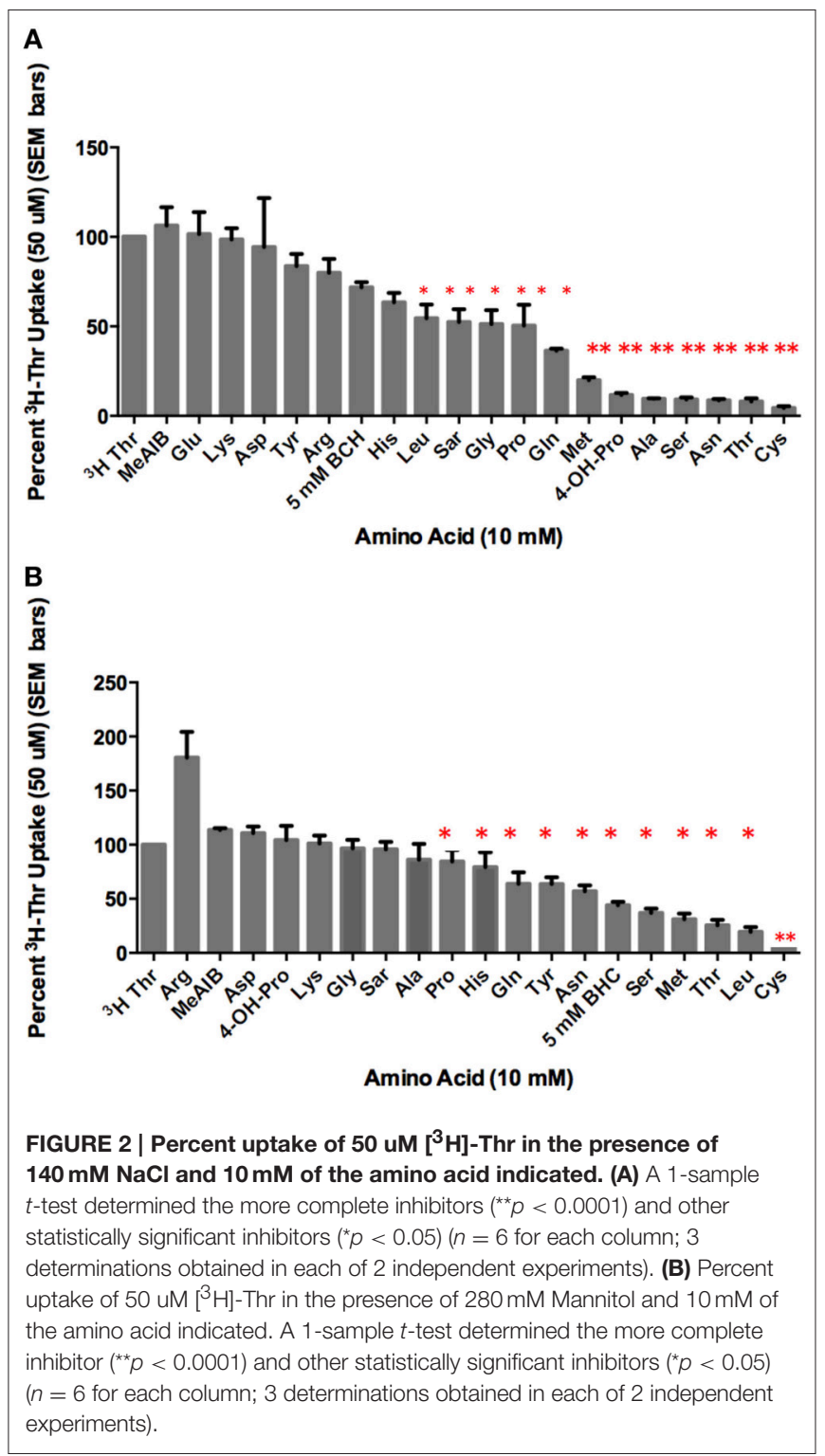

Met, His, Gln, BCH, 4-OH-Pro, and non-radioactive Thr itself (Figure 2A). Of these, the more complete inhibitors were Ser, Thr, Cys, Asn, Ala, Met, and 4-OH-Pro ( $p<0.0001$; Figure 2A). Less complete inhibitors were Gln, Gly, Leu, Pro, His, Sar, and BCH. Arg, Tyr, Glu, Lys, meAIB, and Asp did not inhibit $\left[{ }^{3} \mathrm{H}\right]-$ Thr uptake to a statistically significant extent (Figure 2A). See Table S1 in the supplemental materials for a full list of the amino acids and their abbreviations.

In the absence of $\mathrm{Na}^{+},\left[{ }^{3} \mathrm{H}\right]-\mathrm{Thr}$ transport was significantly inhibited $(p<0.05)$ by Ser, Leu, MeAIB, Thr, Cys, Asn, Met, Gln, Tyr, and BCH (Figure 2B). Notably, Leu, Tyr, and BCH were better inhibitors in the absence than in the presence of $\mathrm{Na}^{+}$, while Asn and Ala were better inhibitors in the presence of $\mathrm{Na}^{+}$(Figure 2A vs. Figure 2B; Table 1). Cys was the strongest inhibitor in both conditions $(p<0.0001)$ (Figures 2A,B). $\left[{ }^{3} \mathrm{H}\right]$ Thr transport was not significantly inhibited by Glu, Lys, Gly, 
TABLE 1 | Mean \% [ $\left.{ }^{3} \mathrm{H}\right]$-Thr Uptake in $140 \mathrm{mM} \mathrm{NaCl}$ vs. $280 \mathrm{mM}$ Mannitol and the amino acid indicated (from Figures 2A,B).

\begin{tabular}{lcc}
\hline Amino acid & NaCl uptake buffer (\%) & Mannitol uptake buffer (\%) \\
\hline Ser & 9.12 & 37.05 \\
Thr & 8.00 & 25.53 \\
Asn & 8.68 & 57.05 \\
Met & 19.90 & 31.10 \\
Gln & 36.44 & 63.90 \\
Leu & 54.53 & 19.48 \\
BCH & 71.78 & 44.13 \\
Tyr & 83.64 & 63.65 \\
Ala & 9.56 & 86.20 \\
Cys & 4.40 & 14.78 \\
\hline
\end{tabular}

MeAIB, Pro, Asp, Sar, Ala, His, Arg, or 4-OH-Pro in the absence of $\mathrm{Na}^{+}$.

\section{Establishing Weaker vs. Partial Inhibition by Leu and Pro}

Of the incomplete inhibitors of Thr uptake in the presence of $\mathrm{Na}^{+}$(Figure 1A), Leu and Pro were found to be weak rather than partial inhibitors. Thr uptake decreased as the Leu or Pro concentration increased to $20 \mathrm{mM}$ (Figures 3A,B) indicating weak inhibition. Because Leu and Pro were weak inhibitors, they probably inhibited the same components of Thr transport. Furthermore, when Leu and Pro combined and examined as inhibitors of Thr uptake, Leu and Pro did not inhibit Thr transport more than Leu or Pro alone (Figure 3C). This confirmed that they were likely inhibiting the same $\mathrm{Thr}$ transporters.

\section{Determining Relative Transporter Affinities for the Stronger Thr Inhibitors}

Amino acids that inhibited $50 \mathrm{uM}$ Thr uptake most completely were identified in Figure 2. Of these, the inhibition by Ser, Ala, non-radiolabeled Thr and Cys were compared at the lower concentration of $500 \mathrm{uM}$ (Figure 4A). After subtracting $\mathrm{Na}^{+}$independent Thr uptake, $500 \mathrm{uM}$ Cys was the strongest inhibitor tested, with a mean proportion of Thr uptake remaining of only 20\% (Figure 4A). However, no statistically significant differences in inhibition were seen amongst the $500 \mathrm{uM} \mathrm{Ser,} \mathrm{Ala,} \mathrm{Thr,} \mathrm{and}$ Cys $(p>0.05)$. Even when the $\mathrm{Na}^{+}$-independent component of transport was not subtracted, the pattern of inhibition was the same (Figure 4A vs. Figure 4B).

In comparing a second set of more complete inhibitors identified in Figure 2A (Asn, Met, 3-HNV, and 4-OH-Pro), 500 $\mathrm{uM}$ 4-OH-Pro was the strongest inhibitor tested, with a mean proportion of Thr uptake remaining of $41 \%$ after subtracting Na+-independent Thr transport (Figure 5A). However, no statistically significant differences in inhibition were found amongst $500 \mathrm{uM}$ Asn, Met, 3-HNV, and 4-OH-Pro $(p>$ $0.05)$. The pattern of inhibition was the same even when the $\mathrm{Na}^{+}$-independent component of transport was not subtracted

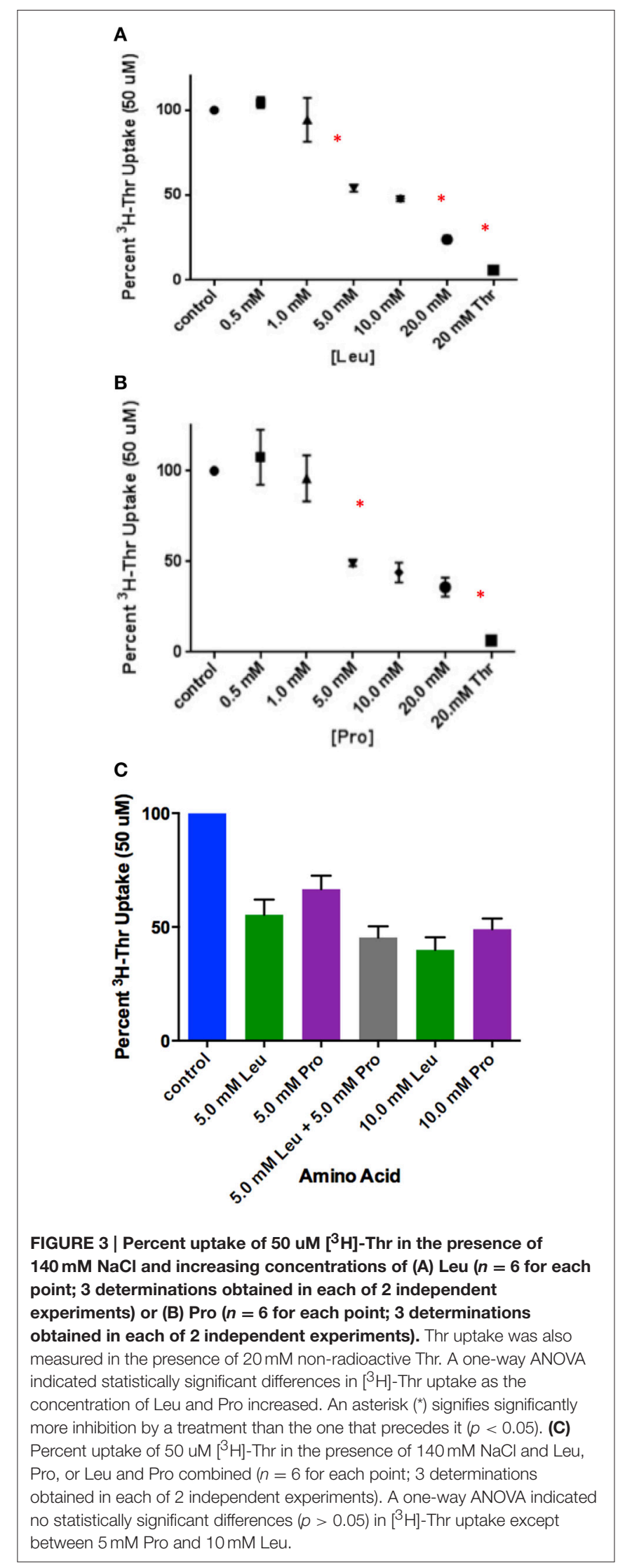



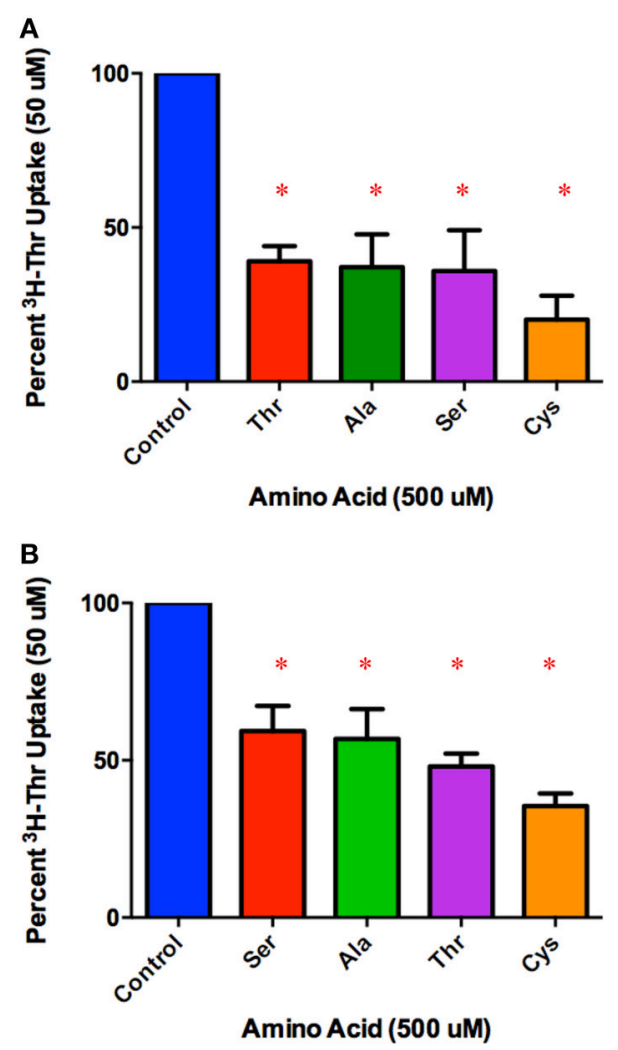

FIGURE 4 | Percent $\mathrm{Na}^{+}$-dependent uptake of $50 \mathrm{uM}\left[{ }^{3} \mathrm{H}\right]-\mathrm{Thr}$ remaining in the presence of the indicated amino acid (500 uM) (A) after subtraction of uptake in $140 \mathrm{mM}$ Choline $\mathrm{Cl}$. A 1-sample $t$-test confirmed that all amino acids tested were s significant inhibitors $\left({ }^{*} p<0.05\right)$. A one-way ANOVA indicated no statistically significant difference in $\left[{ }^{3} \mathrm{H}\right]$-Thr uptake in the presence of the different amino acids tested $(p>0.05)(n=4$ for each column; 2 determinations obtained in each of 2 independent experiments). (B) Percent uptake of $\left[{ }^{3} \mathrm{H}\right]$-Thr remaining in the presence of the indicated amino acid (500 uM) but without subtraction of $\mathrm{Na}^{+}$-independent transport. A 1-sample t-test confirmed that all amino acids were statistically significant inhibitors $\left({ }^{*} p<0.05\right)$. A one-way ANOVA indicated no statistically significant difference in $\left[{ }^{3} \mathrm{H}\right]$-Thr uptake in the presence of the different amino acids tested $(p>0.05)$ ( $n=4$ for each column; 3 determinations obtained in each of 2 independent experiments).

(Figure 5A vs. Figure 5B) although inhibition by 4-OH-Pro was then greater than the other inhibitors tested $(p<0.05)$ (Figure 5B). Additionally, although a good inhibitor, 3-HNV was not one of the strongest inhibitors (Figures 5A,B). For example, $20 \mathrm{mM}$ Ser inhibited $\left[{ }^{3} \mathrm{H}\right]$-Thr uptake almost as much as $20 \mathrm{mM}$ non-radiolabeled Thr (Figure 6A), whereas $20 \mathrm{mM}$ 3-HNV inhibited $\left[{ }^{3} \mathrm{H}\right]$-Thr uptake considerably less completely than did $20 \mathrm{mM}$ non-radiolabeled Thr ( $p<0.05$; Figure 6B).

\section{Determining mRNA Encoding ASCT1/2 via RT-PCR}

Given the findings from our transport studies, it was likely that the $\mathrm{Na}^{+}$-dependent transporters, ASCT1 and/or ASCT2, were responsible for most of the $\mathrm{Na}^{+}$-dependent transport of Thr in mES cells. Upon conducting RT-PCR and gel electrophoresis, we

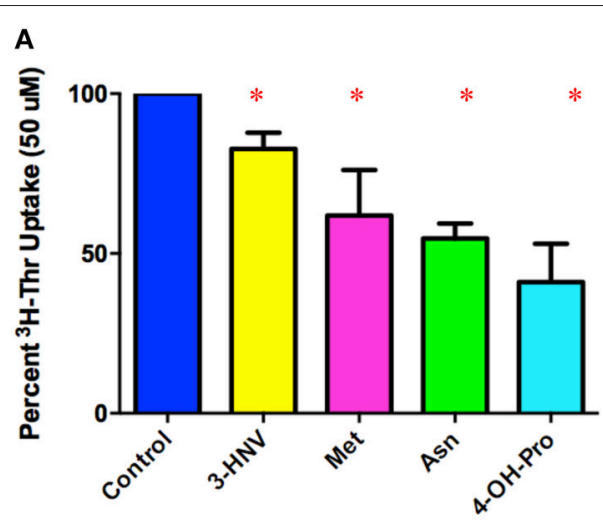

Amino Acid (500 uM)

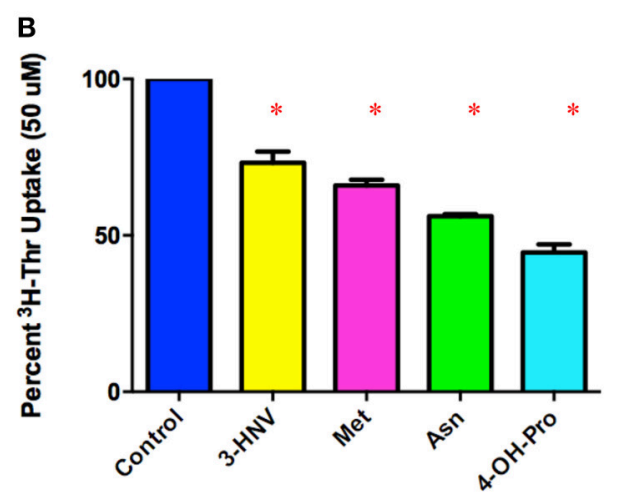

Amino Acid (500 uM)

FIGURE 5 | Percent $\mathrm{Na}^{+}$-dependent uptake of $50 \mathrm{uM}\left[{ }^{3} \mathrm{H}\right]-\mathrm{Thr}$ remaining in the presence of the indicated amino acid (500 uM) (A) after subtraction of uptake in $140 \mathrm{mM}$ Choline $\mathbf{C l}$. A 1-sample $t$-test confirmed that all amino acids were statistically significant inhibitors $\left({ }^{*} p<0.05\right)$. A one-way ANOVA indicated no statistically significant difference in $\left[{ }^{3} \mathrm{H}\right]$-Thr uptake in the presence of the different amino acids tested $(p>0.05)$ ( $n=4$ for each column; 2 determinations obtained in each of 2 independent experiments). (B) Percent uptake of $\left[{ }^{3} \mathrm{H}\right]$-Thr remaining in the presence of the indicated amino acid (500 uM) but without subtraction of $\mathrm{Na}^{+}$-independent transport. A 1-sample $t$-test confirmed that all amino acids were statistically significant inhibitors ( ${ }^{*} p<0.05$ ). A one-way ANOVA indicated 4-OH-Pro inhibited $\left[{ }^{3} \mathrm{H}\right]$-Thr uptake significantly more than the other amino acids tested $(p<0.05)$. ( $n=4$ for each column; 2 determinations obtained in each of 2 independent experiments).

detected cDNA bands of the size anticipated for both ASCT1 and ASCT2 mRNA (Figure 7). The sequences of the cDNAs corresponded exactly to the sequences anticipated for those segments of ASCT1 and ASCT2 mRNA (Molecular Cloning Laboratories) (Data not shown).

\section{DISCUSSION}

\section{mES Cells Express Both $\mathrm{Na}^{+}$-Dependent and $\mathrm{Na}^{+}$-Independent Components of Thr Transport}

As depicted in the time course studies, $\mathrm{Na}^{+}$-dependent $\mathrm{Thr}$ uptake is considerably more rapid than $\mathrm{Na}^{+}$-independent uptake 


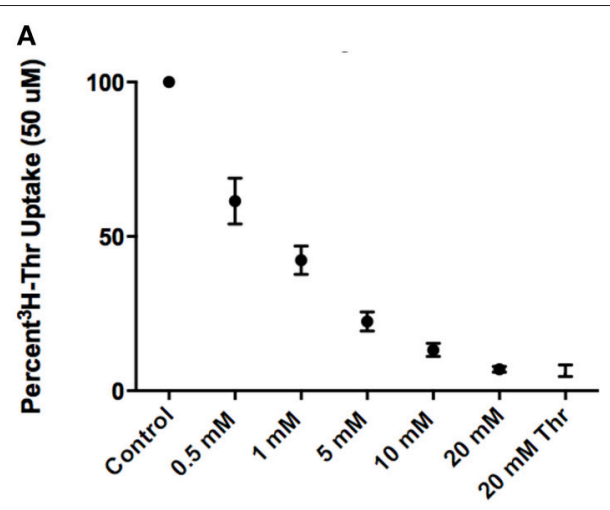

[Ser]

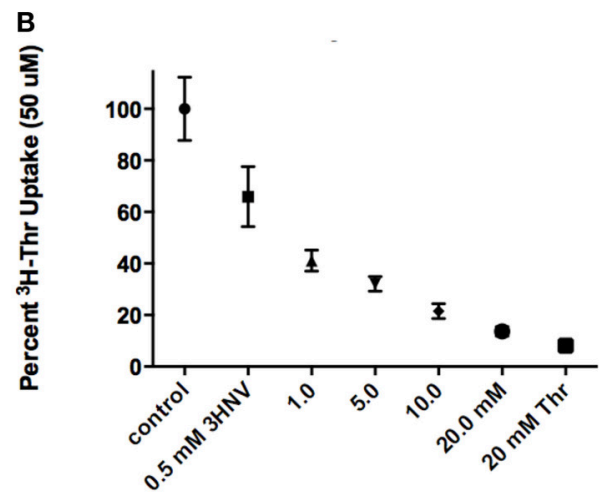

[3-HNV]

FIGURE 6 | Percent uptake of $50 \mathrm{uM}\left[{ }^{3} \mathrm{H}\right]$-Thr in the presence of $140 \mathrm{mM} \mathrm{NaCl}$ and increasing concentrations of (A) Ser or (B) 3-HNV ( $n=6$ for each point; 3 determinations obtained in each of 2 independent experiments). Thr uptake was also measured in the presence of $20 \mathrm{mM}$ non-radiolabeled Thr. A 2-sample $t$-test indicated that $\left[{ }^{3} \mathrm{H}\right]$-Thr uptake in $20 \mathrm{mM}$ Ser was not significantly different from $\left[{ }^{3} \mathrm{H}\right]$-Thr uptake in $20 \mathrm{mM}$ non-radiolabeled $\operatorname{Thr}(p>0.05)$, whereas $\left[{ }^{3} \mathrm{H}\right]$ - Thr uptake in $20 \mathrm{mM}$ 3 -HNV was significantly higher than $\left[{ }^{3} \mathrm{H}\right]$ - Thr uptake in $20 \mathrm{mM}$

non-radiolabeled Thr $(p<0.05)$. A one-way ANOVA also indicated that $50 \mathrm{uM}$ $\left[{ }^{3} \mathrm{H}\right]$-Thr uptake significantly decreased with increasing concentration of Ser or $3-H N V(p<0.05)$.

in mES cells (Figure 1A). Nevertheless, $\mathrm{Na}^{+}$-independent $\mathrm{Thr}$ transport is substrate saturable as there was non-radiolabeled Thr inhibition of $\left[{ }^{3} \mathrm{H}\right]-$ Thr transport in the absence of $\mathrm{Na}^{+}$ (Figure 2B). Hence, mES cells express both $\mathrm{Na}^{+}$-dependent and $\mathrm{Na}^{+}$-independent components of Thr transport.

\section{Amino Acid Inhibition of $\mathrm{Na}^{+}$-Dependent Thr Transport in mES Cells Resembles Such Inhibition of Amino Acid Transport System ASC in Other Cells}

Thr, Ser, Cys, 4-OH-Pro, Asn, and Ala were relatively strong inhibitors of the $\mathrm{Na}^{+}$-dependent $\left[{ }^{3} \mathrm{H}\right]$-Thr transport in mES cells (Figures 2A, 4B, 5B). These amino acids are also relatively strong inhibitors for the ASCT1 and ASCT2 transports in other cell types (Utsunomiya-Tate et al., 1996; Yamamoto et al., 2003, 2004). Specifically, both the $\mathrm{Na}^{+}$-dependent Thr transporter(s)

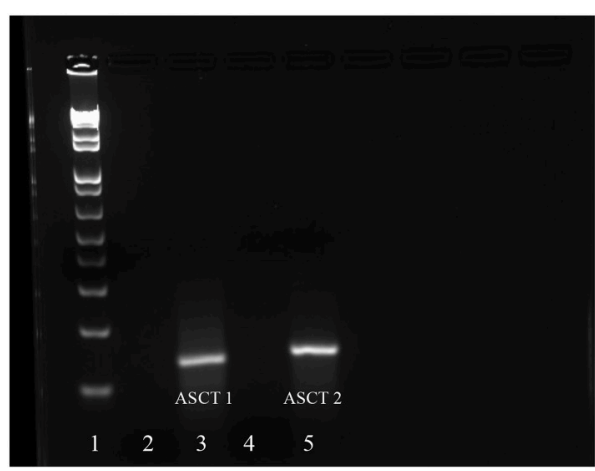

FIGURE 7 | mRNA expression of ASCT1 and ASCT2 in mES cells as determined by RT-RCR. Lane 1: DNA ladder; Lane 2: ASCT1 primers and no RNA template control; Lane 3: ASCT1 primers and template RNA; Lane 4: ASCT2 primers and no template RNA control; Lane 5: ASCT2 primers and template RNA.

in mES cells and the ASC system transporters have a strong preference for neutral amino acids without branched or bulky side chains, with the exception that they tolerate a hydroxyl or sulfhydryl group at C3 or C4 of the amino acid (UtsunomiyaTate et al., 1996; Pinilla-Tenas et al., 2003). Thr, Ser, 3-HNV, Cys, and 4-OH-Pro, share these characteristics. The hydroxylation of Pro at C4 greatly increases its affinity for both the ASC system transporters (Utsunomiya-Tate et al., 1996; Pinilla-Tenas et al., 2003) and the $\mathrm{Na}^{+}$-dependent component of transport in mES cells. For example, $0.5 \mathrm{mM}$ Pro does not inhibit Thr uptake (Figure 3B) whereas this concentration of 4-OH-Pro does inhibit Thr transport (Figure 5B). Asn is another relatively strong inhibitor of $\mathrm{Na}^{+}$-dependent Thr uptake in both mES cells (Figures 2A, 5B) and the ASC system in other cells (UtsunomiyaTate et al., 1996). While Asn does not have a hydroxyl or sulfhydryl group, it does have polar groups on $\mathrm{C} 4$, similar to 4-OH-Pro. This could explain its relatively strong inhibitor properties.

Ala, Met, and Gln were also good inhibitors of $\mathrm{Na}^{+}$-dependent Thr uptake (Figures 2A, 4B, 5B). Ala inhibition could be attributed to its small neutral structure, and both the ASCT1 and ASCT2 transporters are selective for small amino acids (Utsunomiya-Tate et al., 1996). As for Met and Gln inhibition in mES cells, ASCT2 (but not ASCT1) has been shown to interact strongly with both of these amino acids in other cell types (Utsunomiya-Tate et al., 1996; Bröer et al., 1999). Thus, Ala might inhibit both $\mathrm{Na}^{+}$-dependent ASCT1 and ASCT2 transporters in mES cells, while Met and Gln might inhibit mainly ASCT2 in these cells. This could account for the greater inhibition of Thr uptake seen by $10 \mathrm{mM}$ Ala compared to $10 \mathrm{mM}$ Met and Gln (Figure 2A).

Lastly, $10 \mathrm{mM}$ Gly, Leu, Pro, and His were incomplete inhibitors of Thr uptake in mES cells (Figure 2A), and ASCT2 interacts weakly with these amino acids (Utsunomiya-Tate et al., 1996). Specifically, Thr uptake decreased as the Leu or Pro concentration increased to $20 \mathrm{mM}$ (Figures 3A,B), indicating that Leu and Pro were probably inhibiting the same components of Thr transport. Additionally, since Leu and Pro did not 
inhibit Thr transport more when combined than when studied separately (Figure 3C), they were probably inhibiting the same $\mathrm{Na}^{+}$-dependent transporters.

\section{ASCT1 and ASCT2 mRNA are Present in mES Cells}

These findings for Thr transport in mES cells support the theory that the cells express one or both of the system ASC transporters, ASCT1 and ASCT2. RT-PCR and sequencing of the cDNA products confirmed expression of mRNA encoding both ASCT1 and ASCT2 in mES cells (Figure 7). Thus, it is likely that ASCT1 and ASCT2 are responsible for $\mathrm{Na}^{+}$-dependent $\mathrm{Thr}$ transport in mES cells, and that there are at least two components of $\mathrm{Na}^{+}$-dependent transport in the cells.

\section{Amino Acid Inhibition of $\mathrm{Na}^{+}$-Independent Thr Transport in mES Cells Resembles Such Inhibition of Amino Acid Transport System L in Other Cells}

Ser, Leu, Cys, Asn, Met, Gln, Tyr, BCH, and non-radiolabeled Thr inhibited the $\mathrm{Na}^{+}$-independent component of $\left[{ }^{3} \mathrm{H}\right]-\mathrm{Thr}$ transport in mES cells (Figure 2B). Such is also the case for System L transporters in other cell types (Segawa et al., 1999). Furthermore, both the $\mathrm{Na}^{+}$-independent Thr transporter(s) in mES cells (Figure 2B) and System L transporters in other cell types are inhibited strongly and selectively by the Leu analog, BCH (Segawa et al., 1999; Fukasawa et al., 2000; Fuchs and Bode, 2005). Finally, Tyr inhibited Thr transport only in the absence of $\mathrm{Na}^{+}$(Figure 2B). LAT2, a system L transporter with broad substrate selectivity, also interacts with Tyr (Fukasawa et al., 2000; Fuchs and Bode, 2005). Thus, the $\mathrm{Na}^{+}$-independent $\mathrm{Thr}$ transporter(s) in mES cells is likely LAT2 or another system L transporter.

\section{CONCLUSION}

This is the first study to characterize Thr transport by mES cells. Our findings support the conclusion that ASCT1 and ASCT2 are primarily responsible for the $\mathrm{Na}^{+}$-dependent component of $\mathrm{Thr}$ transport in these cells. Because these two transporters are so similar, however, studying them independently for Thr transport in mES cells is difficult. Both are likely present and both probably play roles in transporting Thr into the cells. While there is also a $\mathrm{Na}^{+}$-independent component of Thr transport in mES cells, it was less well characterized in these studies. According to its transport characteristics, however, it is probably a form of amino acid transport system $\mathrm{L}$.

Future studies could explore the $\mathrm{Na}^{+}$-independent component of Thr transport in mES cells in more detail.

\section{REFERENCES}

Alexander, P. B., Wang, J., and McKnight, S. L. (2011). Targeted killing of a mammalian cell based upon its specialized metabolic state. Proc. Natl. Acad. Sci. U.S.A. 108, 15828-15833. doi: 10.1073/pnas.1111312108

Amit, M., Carpenter, M. K., Inokuma, M. S., Chiu, C. P., Harris, C. P., Waknitz, M. A., et al. (2000). Clonally derived human embryonic stem cell lines maintain pluripotency and proliferative potential for
Additionally, now that the transporters responsible for the majority of Thr transport into mES cells have been identified, future studies should explore the effect Thr transport inhibitors have on the growth of $\mathrm{mES}$ cells. If $\mathrm{mES}$ cell growth is arrested when Thr transport is inhibited by other amino acids such as Ser, Cys, or Ala, then this would support the conclusion that Thr transport mediates Thr's effects in controlling mES cell proliferation. In this regard, our preliminary studies show that both Ser and 3-HNV inhibit proliferation of mES cells, although Ser inhibition is not nearly as strong as that of 3-HNV (Rasmussen and Van Winkle, personal communication). In this regard, the stoichiometry of $\mathrm{Na}^{+}$/amino acid cotransport by system ASC varies from 4.5 to 0.22 depending on the structure of the amino acid (Van Winkle, 2001). Such variable interactions of amino acids with the ASC transport protein could also mean that they influence signaling initiated by the protein (Ryu and Han, 2011) in different ways or to varying extents. Moreover, it would be interesting in future studies to knockdown either or both ASCT1 or ASCT2 expression and measure the effects of such knockdowns on mES cell proliferation.

\section{AUTHOR CONTRIBUTIONS}

TF is the primary author/researcher on this paper. She conducted all experiments and did all the writing for the project under the guidance of her primary investigator, LV. LV and TF worked together to develop the project, protocols for the experiments, and analysis of results.

\section{FUNDING}

Midwestern University Department of Biomedical Sciences provided all funding for this project.

\section{ACKNOWLEDGMENTS}

We thank Drs. Sophie La Salle and Nalini Chandar for their roles as thesis advisors for this project. We also thank Al Campione, Lenore Pitstick, and Timothy Doolin for their assistance with the experiments. Additionally, we thank Dr. Jacob Peuler for his help with the statistics. Lastly, we thank the Midwestern University Biomedical Sciences Program for funding our work.

\section{SUPPLEMENTARY MATERIAL}

The Supplementary Material for this article can be found online at: http://journal.frontiersin.org/article/10.3389/fcell. 2016.00017

prolonged periods of culture. Dev. Biol. 227, 271-278. doi: 10.1006/dbio. 2000.9912

Bröer, A., Brookes, N., Ganapathy, V., Dimmer, K. S., Wagner, C. A., Lang, F., et al. (1999). The astroglial ASCT2 amino acid transporter as a mediator of glutamine efflux. J. Neurochem. 73, 2184-2194.

Darling, P. B., Grunow, J., Rafii, M., Brookes, S., Ball, R. O., and Pencharz, P. B. (2000). Threonine dehydrogenase is a minor degradative pathway of threonine catabolism in adult humans. Am. J. Physiol. Endocrinol. Metab. 278, E877-E884. 
Edgar, A. J. (2002). The human L-threonine 3-dehydrogenase gene is an expressed pseudogene. BMC Genet. 3:18. doi: 10.1186/1471-2156-3-18

Fuchs, B. C., and Bode, B. P. (2005). Amino acid transporters ASCT2 and LAT1 in cancer: partners in crime? Semin. Cancer Biol. 4, 254-266. doi: 10.1016/j.semcancer.2005.04.005

Fukasawa, Y., Segawa, H., Kim, J. Y., Chairoungdua, A., Kim, D. K., Matsuo, H., et al. (2000). Identification and characterization of a $\mathrm{Na}^{+}$-independent neutral amino acid transporter that associates with the $4 \mathrm{~F} 2$ heavy chain and exhibits substrate selectivity for small neutral D- and L- amino acids. J. Biol. Chem. 275, 9690-9698. doi: 10.1074/jbc.275.13.9690

Han, C., Gu, H., Wang, J., Lu, W., Mei, Y., and Wu, M. (2013). Regulation of L-threonine dehydrogenase in somatic cell reprogramming. Stem Cells 31, 953-965. doi: 10.1002/stem.1335

Marin, M., Tailor, C. S., Nouri, A., and Kabat, D. (2000). Sodium-dependent neutral amino acid transporter type 1 is an auxiliary receptor for baboon endogenous retrovirus. J. Virol. 74, 8085-8093. doi: 10.1128/JVI.74.17.8085-8093.2000

Ochocki, J. D., and Simon, M. C. (2013). Nutrient-sensing pathways and metabolic regulation in stem cells. J. Cell Biol. 203, 23-33. doi: 10.1083/jcb.201303110

Pinilla-Tenas, J., Barber, A., and Losato, M. P. (2003). Transport of proline and hydroxyproline by the neutral amino-acid exchanger ASCT1. J. Membr. Biol. 195, 27-32. doi: 10.1007/s00232-003-2041-9

Placín, M., Esteves, R., Bertran, J., and Zorzano, A. (1998). Molecular biology of mammalian plasma membrane amino acid transporters. Physiol. Rev. 78, 969-1054.

Puri, M. C., and Nagy, A. (2012). Concise review: embryonic stem cells versus induced pluripotent stem cells: the game is on. Stem Cells 30, 10-14. doi: $10.1002 /$ stem.788

Ryu, J. M., and Han, H. J. (2011). L-threonine regulates G1/S phase transition of mouse embryonic stem cells via PI3K/Akt, MAPKs, and mTORC pathways. J. Biol. Chem. 286, 23667-23678. doi: 10.1074/jbc.M110.216283

Segawa, H., Fukasawa, Y., Miyamato, K., Takedo, E., Endou, H., and Kanai, Y. (1999). Identification and functional characterization of a $\mathrm{Na}^{+}$-independent neutral amino acid transporters with broad substrate selectivity. J. Biol. Chem. 274, 19745-19751. doi: 10.1074/jbc.274.28.19745
Utsunomiya-Tate, N., Endou, H., and Kanai, Y. (1996). Cloning and functional characterization of systen ASC-like $\mathrm{Na}^{+}$-dependent neutral amino acid transporter. J. Biol. Chem. 271, 14883-14890. doi: 10.1074/jbc.271.25.14883

Van Winkle, L., Galat, V., and Iannaccone, P. (2014). Threonine appears to be essential for proliferation of human as well as mouse embryonic stem cells. Front. Cell Dev. Biol. 2:18. doi: 10.3389/fcell.2014.00018

Van Winkle, L. J. (2001). Importance of direct determination of amino acid C0- and counter-transport stoichiometry. Amino Acids 20, 105-111. doi: $10.1007 / \mathrm{s} 007260170051$

Van Winkle, L. J. (2013). "Amino acid transporters: roles for nutrition and signalling in embryonic and induced pluripotent stem cells," in eLS (John Wiley \& Sons, Ltd.).

Wang, J., Alexander, P., Wu, L., Hammer, R., Cleaver, O., and McKnight, S. L. (2009). Dependence of mouse embryonic stem cells on threonine catabolism. Science 325, 435-439. doi: 10.1126/science.1173288

Yamamoto, T., Nishizaki, I., Furuya, S., Hirabayashi, Y., Takahashi, K., Okuyama, S., et al. (2003). Characterization of rapid and high-affinity uptake of L-serine in neurons and astrocytes in primary culture. FEBS Lett. 548, 69-73. doi: 10.1016/S0014-5793(03)00742-7

Yamamoto, T., Nishizaki, I., Nukada, T., Kamegaya, E., Furuya, S., Hirabayashi, Y., et al. (2004). Functional identification of ASCT1 neutral amino acid transporter as the predominant system for the uptake of L-serin in rat neurons in primary culture. Neurosci. Res. 49, 101-111. doi: 10.1016/j.neures.2004.02.004

Conflict of Interest Statement: The authors declare that the research was conducted in the absence of any commercial or financial relationships that could be construed as a potential conflict of interest.

Copyright (ㅇ) 2016 Formisano and Van Winkle. This is an open-access article distributed under the terms of the Creative Commons Attribution License (CC BY). The use, distribution or reproduction in other forums is permitted, provided the original author(s) or licensor are credited and that the original publication in this journal is cited, in accordance with accepted academic practice. No use, distribution or reproduction is permitted which does not comply with these terms. 